Research Article

\title{
Experimental Investigation on Hard Rock Breaking with Fiber Laser: Surface Failure Characteristics and Perforating Mechanism
}

\author{
Xiaofeng Yang ${ }^{D}$, Xin Zhou, Hongliang Zhu, Jiaheng Zhou, and Yanhong Li \\ School of Mechanics and Civil Engineering, China University of Mining and Technology, Beijing 100083, China \\ Correspondence should be addressed to Xiaofeng Yang; act777@126.com
}

Received 17 January 2020; Revised 3 April 2020; Accepted 18 April 2020; Published 29 April 2020

Academic Editor: Annan Zhou

Copyright (C) 2020 Xiaofeng Yang et al. This is an open access article distributed under the Creative Commons Attribution License, which permits unrestricted use, distribution, and reproduction in any medium, provided the original work is properly cited.

\begin{abstract}
The rock-breaking characteristics and the influence factors of laser perforation are investigated in this study. A series of fiber laser perforation experiments on basalt, sandstone, and granite were conducted. Experimental measurements of rock failure morphologies and composition tests showed that the main surface features are thermal cracks and glazed layer formed by the melting and condensing of rock in laser perforation. It is also found that higher quartz content could help reduce the glazed degree of rock. Comprehensive results showed that the laser rock perforation is mainly formed by thermal fractures, the decline of molten pool, and the evaporating and splashing of the special melted rock components. The depth of rock perforation and SE usually increase with the laser irradiation time, while the ROP gradually decreases. With the increase of laser power, the perforation depth and ROP gradually increase, while the SE initially decreases and then increases indicating that there is an optimal power that maximizes perforation efficiency. It is believed that the strength of rock is the main factor affecting laser perforation efficiency, and the lower rock strength resulted in deeper perforation depth, higher ROP, and lower SE.
\end{abstract}

\section{Introduction}

The demand of development of deep mineral resources and underground engineering is increasing fast worldwide, while the traditional drilling technology is difficult to solve the drilling problem in the deep complex strata effectively. In recent years, laser technology has shown very good application prospect in efficient hard rock breaking and become a research hotspot, with the advantages of low cost, high efficiency and reliability in oil and gas reservoirs and geotechnical engineering [1-9].

Many scholars have carried out experimental studies on the efficiency and effect factors of laser rock breaking. Graves [10] compared the specific energy (SE) of high-power laser drilling with traditional drilling methods and studied the impacts of rock structure, sample shape, and test conditions on sandstone on the SE. Laser perforation experiments on different types of rock showed that there was an optimal set of laser parameters for each rock to minimize the breaking $\mathrm{SE}$, which was generally located in the peeling zone before melting [11]. Besides, the impacts of laser power, frequency, mode of irradiation, auxiliary gas pressure, characteristics, and the SE of rock were studied experimentally, and the surface cracks of rocks were quantitatively characterized [12-18].

In order to reveal the mechanism of laser rock breaking, the relevant mechanical properties of rocks after laser irradiation were also studied. Graves and Batarseh et al. studied the impacts of high-power laser on rock strength and mechanical properties, and the results showed that the high temperature increased the porosity and permeability of the rock and reduced the strength of the rock $[19,20]$. The impacts of complex changes of rock vapor, plasma, and molten pool on rock properties during the laser perforation process were studied with the highspeed video imaged [21]. Jamali and Han et al. carried out an experimental study on the feasibility of the laser heat treatment to weaken the rock structure, and the results showed that the rock strength had obviously weakened after laser irradiation, and the drillability of rock was 
greatly reduced $[22,23]$. In addition, the impact on porosity, cracks evolution, and strength performance of rock after laser irradiation was studied by computed tomography (CT) [24]. However, due to the limitation of experimental methods, most studies are limited to the comparative analysis of rock state before and after laser irradiation; there is a lack of the research about the detailed thermal breaking process and the evolution mechanism.

$\mathrm{Hu}$ et al. attempted to conduct numerical analysis on the temperature distribution of rock surface after laser irradiation and found that the laser perforation efficiency decreased with the increase of irradiation time [25]. A numerical model for predicting the transient thermal behavior of rock during laser perforation was proposed, and the influence rules of laser power and irradiation time on the SE of volume removal were revealed [26]. Based on numerical simulation, it was found that large thermal stress was generated at the location of sudden temperature change in rock during the perforation process, and the initial zone of microcracks was predicted [27]. Li and Ndeda et al. established the finite element model; the causes of microcracks and the impact of thermal stress on the cracks extending were studied based on the analysis of the thermal stress during the granite perforation [28-30]. However, the current numerical simulation studies lack a complete description of the phase transition process of rock under the laser irradiation, which could not systematically reflect the specific process of rock laser perforation.

In summary, current experimental studies mainly focus on the impact of technological parameters on rock breaking efficiency. Furthermore, relevant theoretical studies are limited to the structural and performance changes of rocks before and after laser irradiation, and the complex phase transition process and fracture mechanism of rock have not been studied.

This study carried out laser perforation experiments on basalt, sandstone, and granite, combined with scanning electron microscopy and X-ray diffraction to tests. By analyzing the breaking morphologies of laser perforation surface and comparing the changes of mineral composition before and after laser irradiation, the fracture mechanism of rock surface is summarized. In addition, based on the analysis of the impacts of laser parameters on perforation depth and the whole evolution process of laser perforation formation, the mechanism of rock laser perforation is revealed.

\section{Experiment Procedure}

The rock samples are basalt, sandstone, and granite processed with the size of $4.5 \mathrm{~mm} \times 4.5 \mathrm{~mm} \times 3.5 \mathrm{~mm}$ and characterized for uniaxial compressive strength, shear strength, and thermal conductivity tests (Table 1). A fiber laser perforator with $50 \mathrm{~W}$ is adopted in the experiments (Figure 1). The fixed defocusing amount is $160 \mathrm{~mm}$, and the radius of irradiation zone is $2 \mathrm{~mm}$. The parameters of the irradiation time and laser power are changed in the laser perforation experiments on three kinds of rocks (Tables 2 and 3 ).

When the laser begins to act on the rock surface, the perforation area reacts violently with sizzling sounds. The rock gradually melts, accompanied by white smoke and many tiny splashing molten drops, and some white flocculent. After the irradiation, much small rock particles remain around the rock. After completion of laser perforation, the macromorphologies of the perforation and the surrounding zone are observed with a magnifying glass, and the depth of perforation are measured by a depth meter. The micromorphologies of perforation and characteristics of perforation edge cracks are observed by a scanning electron microscope (SEM). In addition, XRD is used to detect the components of the rock samples before and after the experiments.

\section{Results and Discussion}

\subsection{Failure Mechanisms Contributing to the Rock by Fiber Laser Irradiation}

3.1.1. Failure Characteristics of Basalt by Fiber Laser Irradiation. The surface morphologies of basalt after laser perforation are shown in Figure 2. The original basalt rock is compact in texture with many pores (Figure 2(b)). A smooth glazed layer is formed on the inner wall of perforation, where there also are many holes with many cracks around and a small number of broken vacuoles in local areas (Figure 2(c)). Besides, perforation edge cracks are also obvious (Figure 2(d)). XRD test results of basalt samples before and after laser perforation are shown in Table 4. It is shown that there are no new mineral formations; the main reaction during laser perforation is the mutual transformation of feldspar minerals.

According the analysis of experimental results, there are many tight pores in the original rock which seal a small amount of gas. With the rock melting, some of the gas escapes and blows up to be vacuoles, which grow up and break with the heating process. The molten material condenses to form a smooth glazed layer, which remain on some holes and vacuoles. In addition, the thermal stress generated by the intense temperature difference forms stress concentration around the holes, causing the cracks to appear and extend outwards, and then forming a complex cracks net.

3.1.2. Failure Characteristics of Sandstone by Fiber Laser Irradiation. The surface morphologies of sandstone after laser perforation are shown in Figure 3. The original sandstone is relatively loose with many loose pores (Figure 3(b)). A smooth glazed layer is generated on the surface after perforation, and there also are many holes on the inner wall of the perforation (Figure 3(c)). Cracks exist on the surface of the glazed layer and perforation edge (Figure 3(d)). XRD compositions test results of sandstone samples before and after laser perforation are shown in Table 5. 
TABLE 1: Mechanical and thermal properties of rock samples.

\begin{tabular}{lccc}
\hline & Density $\left(\mathrm{g} / \mathrm{cm}^{3}\right)$ & Heat conductivity $(\mathrm{W} / \mathrm{Mk})$ & Compressive strength $(\mathrm{MPa})$ \\
\hline Basalt & 2.61 & 1.62 & 206.71 \\
Sandstone & 2.34 & 3.24 & 143.08 \\
Granite & 2.44 & 2.51 & 94.22 \\
\hline
\end{tabular}

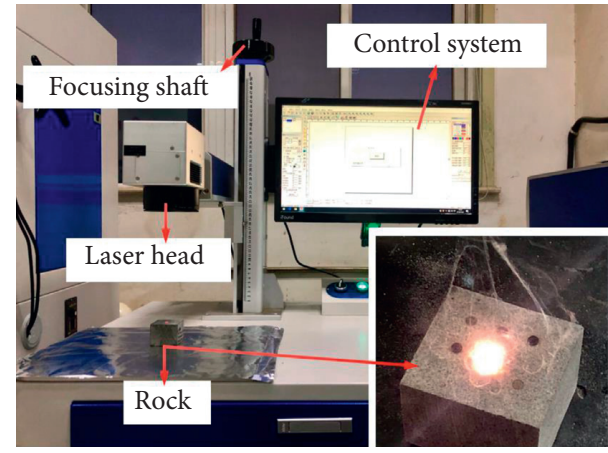

FIGURE 1: Experimental diagram of fiber laser perforation system.

TABLE 2: Experimental parameters of laser irradiation time (laser power $45 \mathrm{~W}$ ).

\begin{tabular}{lllllll}
\hline Rock sample & \multicolumn{5}{c}{ Time (s) } \\
$\begin{array}{l}\text { Basalt } \\
\begin{array}{l}\text { Sandstone } \\
\text { Granite }\end{array}\end{array}$ & 5 & 10 & 15 & 20 & 25 & 30 \\
\hline
\end{tabular}

TABLE 3: Experimental parameters of laser power (irradiation time $15 \mathrm{~s})$.

\begin{tabular}{lllllll}
\hline Rock sample & \multicolumn{5}{c}{ Power (W) } \\
\hline $\begin{array}{l}\text { Basalt } \\
\text { Sandstone }\end{array}$ & 20 & 25 & 30 & 35 & 40 & 45 \\
Granite & & & & & & \\
\hline
\end{tabular}

During melting, calcite $\left(\mathrm{CaCO}_{3}\right)$ and laumontite $(\mathrm{Ca}$ [AlSi $\left.\mathrm{O}_{6}\right] \cdot \mathrm{H}_{2} \mathrm{O}$ ) decompose to produce $\mathrm{CO}_{2}$ and $\mathrm{H}_{2} \mathrm{O}$ (water vapor), and a small amount of gas in the original rock pores escape from the glazed pool. Due to the high content of quartz in the sandstone, the viscosity of the molten glaze is reduced, the vacuoles are not easy to appear, and the gas directly escapes, resulting in many small holes in the glazed layer after condensation. Under the concentration of thermal stress around the holes, microcracks appear and extend to perforation edge.

\subsubsection{Failure Characteristics of Granite by Fiber Laser} Irradiation. The surface morphologies of granite after laser perforation are shown in Figure 4. The original granite is relatively compact with fewer primary pores (Figure 4(b)). Compared with basalt and sandstone, granite generates less glazed material which is distributed in local clusters (Figure 4(a)). A certain number of holes can be seen on the glazed clusters (Figure 4(c)). And there are also obvious cracks in the perforation edge (Figure 4(d)). XRD test results of granite samples before and after laser perforation are shown in Table 6.

It can be inferred from the experimental results that the high content of quartz (melting point $1750^{\circ} \mathrm{C}$ ) in the granite reduce the glazed degree, and the holes on the glazed clusters are mainly caused by $\mathrm{CO}_{2}$ produced by thermal decomposition of calcite $\left(\mathrm{CaCO}_{3}\right)$ for fewer pores in the original granite. The cracks on the perforation edge are also caused by the thermal stress.

The quartz content and glazed degree of basalt, sandstone, and granite in perforation are shown in Figure 5. It is shown that the higher the quartz content in the rock, the lower the glazed degree in the laser perforating. In fact, the melting of quartz needs to absorb a large amount of heat for its high melting point, which increases the difficulty of rock glazing, and the low viscosity of molten quartz also hinders the bonding of the glazed layer. Therefore, the higher quartz content in the rock could help to reduce the glazed degree in the perforation.

In summary, the smooth glazed layer and the formed holes and vacuoles are the main surface characteristics after the laser perforation. The glazed layer is mainly formed by rock melting and condensing, while the formed holes and vacuoles are related to the pore structure and mineral compositions of the original rock. Specially, the quartz content has an important impact on the glazed degree of the laser-acted rock, and the increase of quartz content could reduce the glazed degree.

\subsubsection{Failure Process of the Rock by Fiber Laser Irradiation.} The formation process of rock surface cracks under laser perforation is shown by Figure 6, which could be summarized into four stages. Initially, the temperature of rock increases gradually after the laser irradiation, and the affected zones could be divided into irradiation zone, transitional zone, and heat-affected zone (Figure 6(a)). Then the temperature in the irradiation zone rises sharply to the melting point of the rock, and the rock begins to melt. And a small amount of bubbles appear in the molten pool (Figure 6(b)), due to the escape of the sealed gases in the original pores and the thermally decomposed gases of special mineral components (silicate, etc.). With the increase of irradiation time, the temperature continues to rise and the molten pool gradually boils, the number of bubbles increases, and bubbles constantly grow and break. The temperature of heat-affected zone further increases, and the area of the transitional zone largens and appears to some microcracks (Figure 6(c)). After the laser irradiation, the molten pool condenses to form a smooth glazed layer where some bubbles remain and partly transform to holes. Meanwhile, the microcracks appear around the holes and 


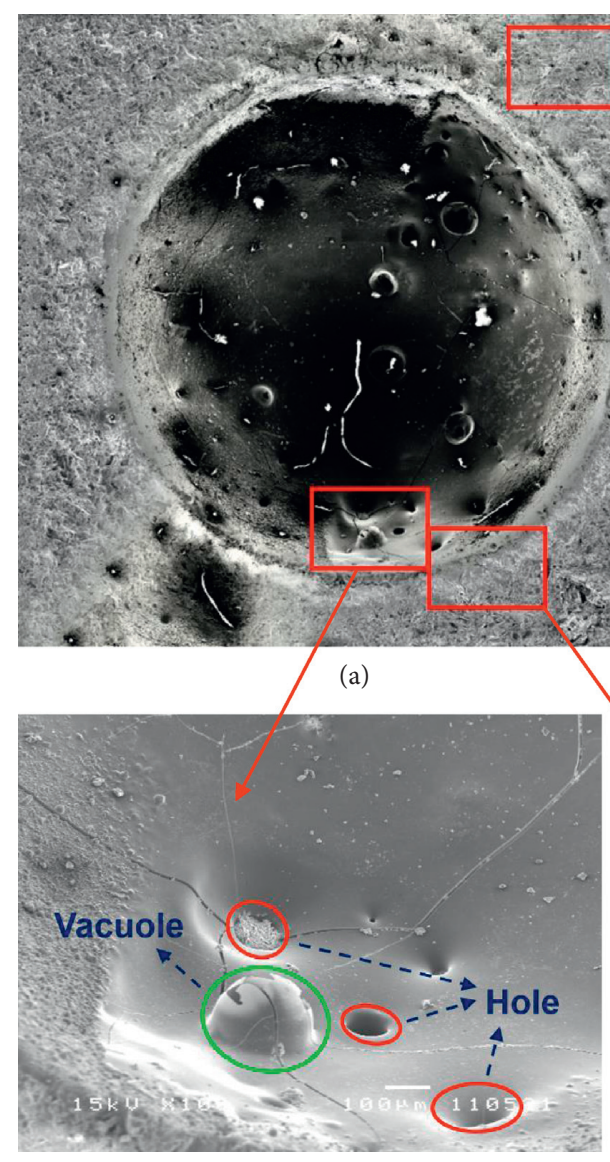

(c)

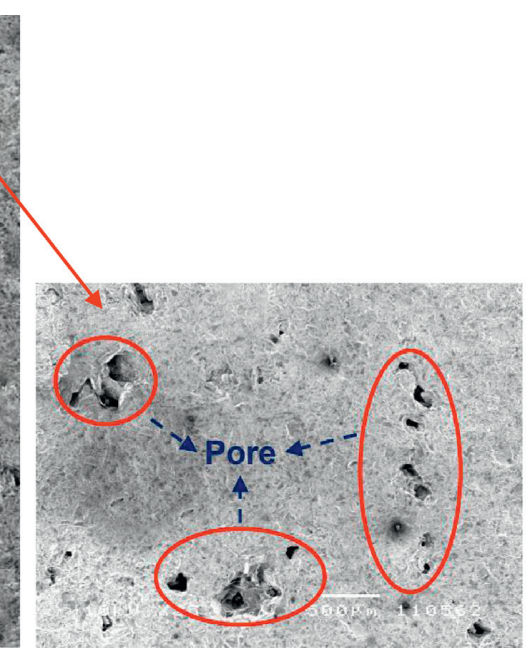

(b)

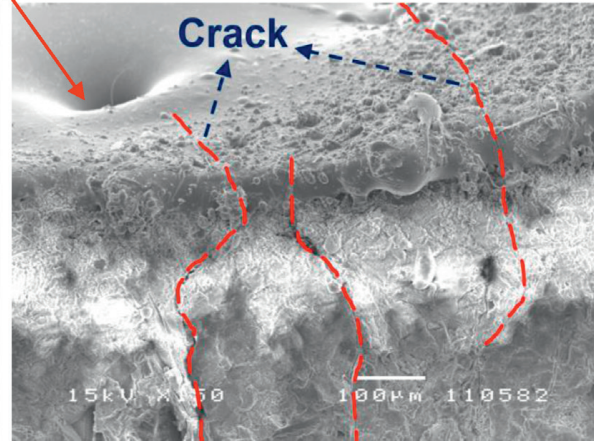

(d)

Figure 2: Surface morphologies of basalt by fiber laser irradiation. (a) Full view of laser perforation. (b) Nonirradiated surface. (c) Holes and vacuoles in the glazed layer. (d) Cracks on the edge of perforation.

TABLE 4: Compositions of basalt before and after laser perforation.

\begin{tabular}{lccc}
\hline & Labradorite (\%) & Plagioclase (\%) & Clay (\%) \\
\hline Basalt & 63.6 & 27.9 & 8.5 \\
Lased & 56.8 & 40.0 & 3.2 \\
\hline
\end{tabular}

rapidly extend outward to form a complex cracks net by the thermal stress (Figure 6(d)).

\subsection{Perforation Mechanism of Rock by Fiber Laser}

3.2.1. Effect of the Laser Irradiation Time in Laser Perforating. The laser perforation surface morphologies of basalt, sandstone, and granite under different irradiation time observed by magnifying glass are shown in Figure 7. It is shown that the perforation depth of basalt, sandstone, and granite gradually deepen with the increase of the irradiation time, and the smooth glazed layer in the hole gradually increases, but the glazed degree in the hole of basalt is significantly higher than sandstone and granite.

As shown in the Figure 8, the rock perforation depth increases with the laser irradiation time. And in the same irradiation time, the perforation depth of granite is the largest, while the basalt is the smallest. This is mainly caused by the difference of rock strength. Higher rock strength means more energy for rock breaking, so the perforation depth is smaller for the harder rock under the same laser energy. Combining with the experimental results of glazed surface, it reveals that the laser perforation depth is also closely related to the glazed degree of the rock, and lower glazed degree results in higher perforation depth. In addition, we also find that granite and sandstone enter the stagnation stage of perforation depth earlier. This is mainly due to the high viscosity and poor thermal conductivity of the molten glaze in granite and sandstone, which influences the further conduction of laser heat into the rock. Furthermore, the higher quartz content in the granite and sandstone improves the heat absorption, which induces them into the earlier depth stagnation.

As we know, specific energy (SE) is an important parameter during laser perforation, which is defined as the amount of energy required to remove a unit volume of rock $[11,14]$ :

$$
\mathrm{SE}=\frac{E}{V}
$$

where $E$ is the input energy and $V$ is the removed volume of the rock sample. 


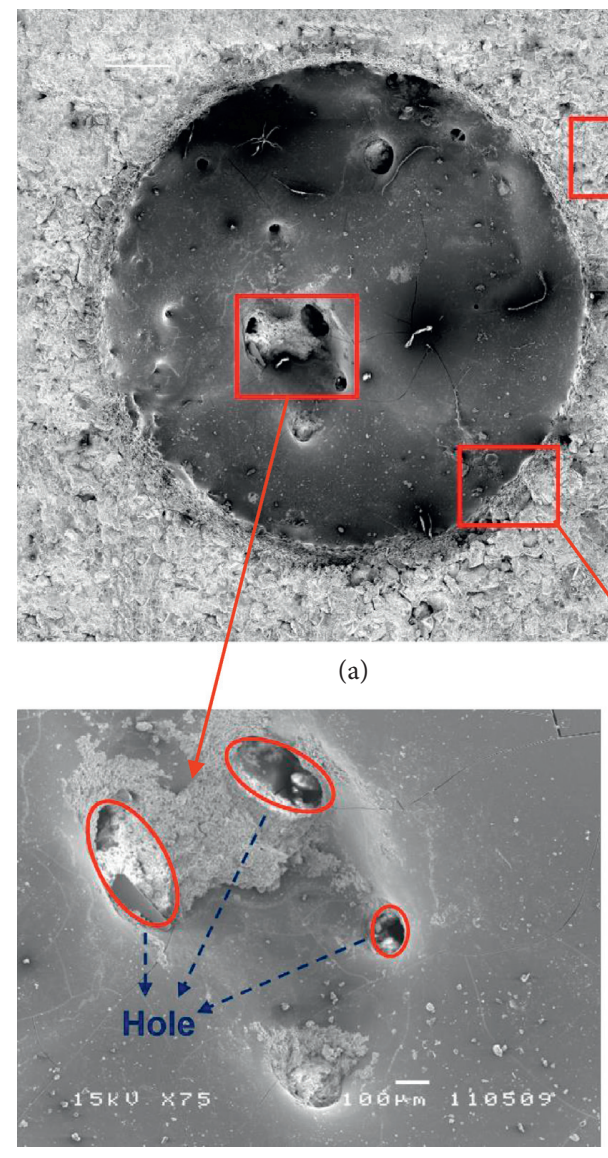

(c)

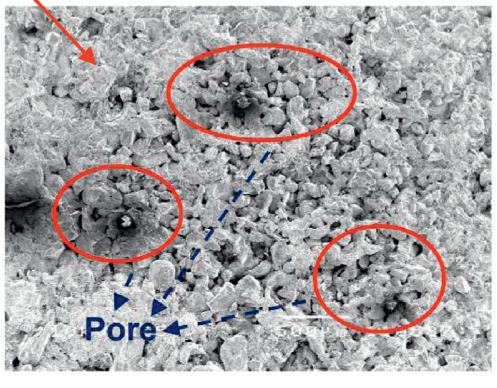

(b)

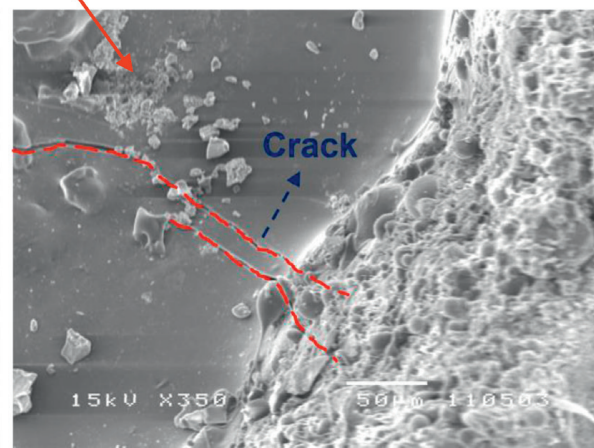

(d)

Figure 3: Surface morphologies of sandstone by fiber laser irradiation. (a) Full view of laser perforation. (b) Nonirradiated surface. (c) Holes in glazed layer. (d) Cracks on the edge of perforation.

TABLE 5: Compositions of sandstone before and after laser perforation.

\begin{tabular}{lccccccc}
\hline & Quartz (\%) & Potassium-feldspar (\%) & Plagioclase (\%) & Calcite (\%) & Hematite (\%) & Laumontite (\%) & Clay (\%) \\
\hline Sandstone & 37.0 & 6.2 & 42.7 & $2.3 \%$ & 3.3 & 0.9 & 7.6 \\
Lased & 13.8 & 1.8 & 57.4 & - & 7.4 & - & 19.6 \\
\hline
\end{tabular}

$$
E=t \times W
$$

where $t$ is the laser irradiation time, and $W$ is the laser power.

The relationship between specific energy (SE) and laser irradiation time is shown in Figure 9. It is showed that the specific energy increases with the irradiation time. The reason is that more glazed layer is produced with the irradiation time, which prevents the laser energy further transmitting to the perforation bottom, and more energy is required for breaking same volume of rock. In addition, under the same irradiation time, the specific energy of basalt is higher than that of sandstone and granite; this is mainly due to the higher strength and of basalt, which requires more energy for breaking.

Another parameter introduced during laser perforation is the rate of penetration (ROP), which contributes to determining the efficiency of laser perforating and calculating cost $[11,14]$. ROP is quantified as

$$
\mathrm{ROP}=\frac{h}{t}
$$

where $h$ and $t$ are the depth of laser perforation and the laser irradiation time, respectively.

Figure 10 exhibits the correlation between laser perforation rate and irradiation time. It can be seen that ROP decreases gradually with the extension of laser irradiation time. This is because the rock gradually melts and produces more glazed layer, which blocks the laser energy transfer and causes a considerable ROP reduction. Furthermore, it is also shown that ROP declines rapidly in the early stage and then decline slows down. At the beginning of perforation, the laser irradiates the rock directly and most laser energy is absorbed by the rock to induce a high perforation rate. Then, more rock is melted to be glazed which hinders the transmission of laser energy. Therefore, ROP decreases rapidly in the early stage, while after the glazed layer forming, the heat absorption tends to be stable, and ROP decreases slowly. In 

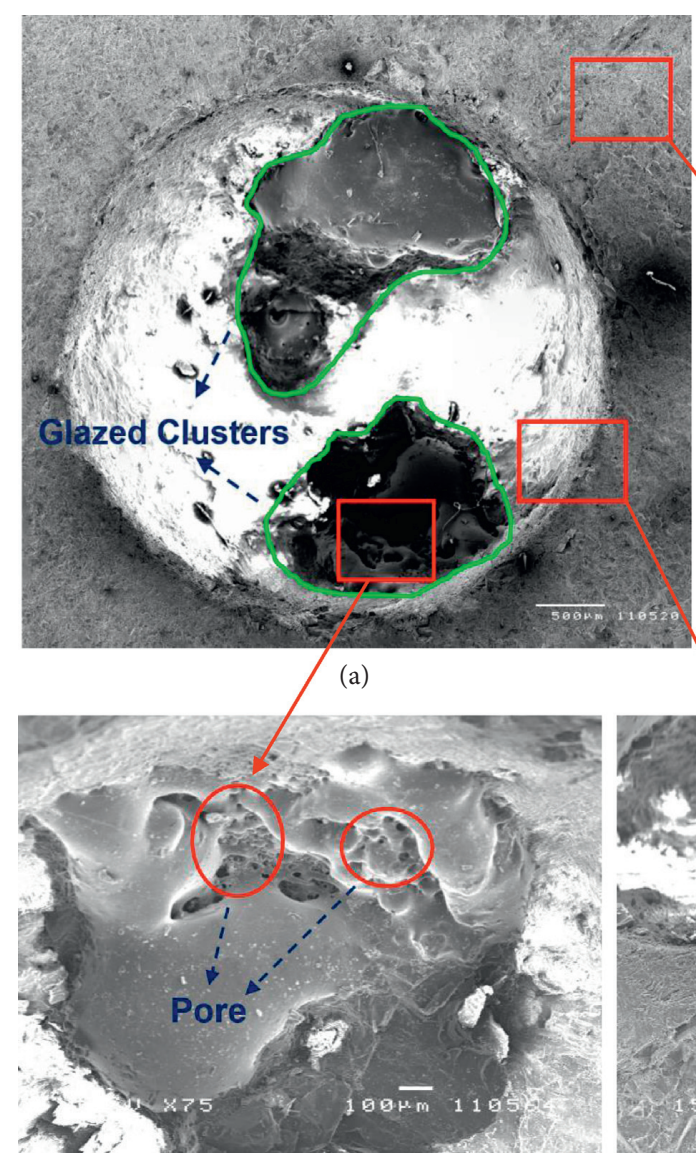

(c)

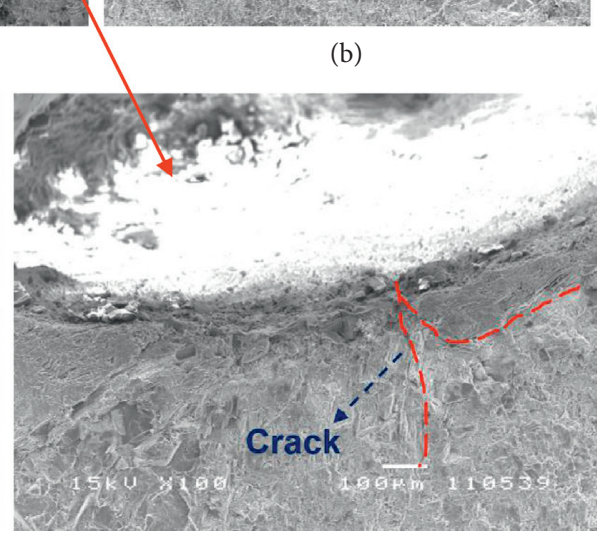

(d)

FiguRE 4: Surface morphologies of granite by fiber laser irradiation. (a) Full view of laser perforation, (b) Nonirradiated surface. (c) Glazed clusters on the perforation surface. (d) Cracks on the edge of perforation.

TABLE 6: Compositions of granite before and after laser perforation.

\begin{tabular}{lccccc}
\hline & Quartz (\%) & Potassium-feldspar (\%) & Plagioclase (\%) & Calcite (\%) & Clay (\%) \\
\hline Granite & 49.5 & 6.5 & 22.7 & 1.6 & 19.7 \\
Lased & 34.0 & 34.6 & 17.7 & - & 13.7 \\
\hline
\end{tabular}

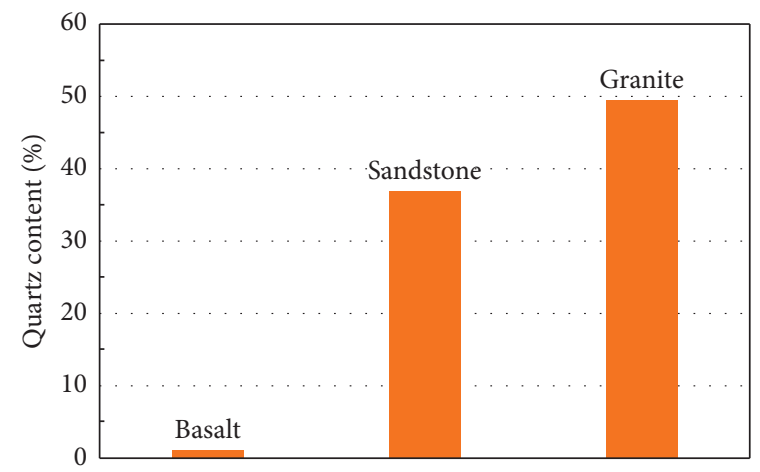

(a)

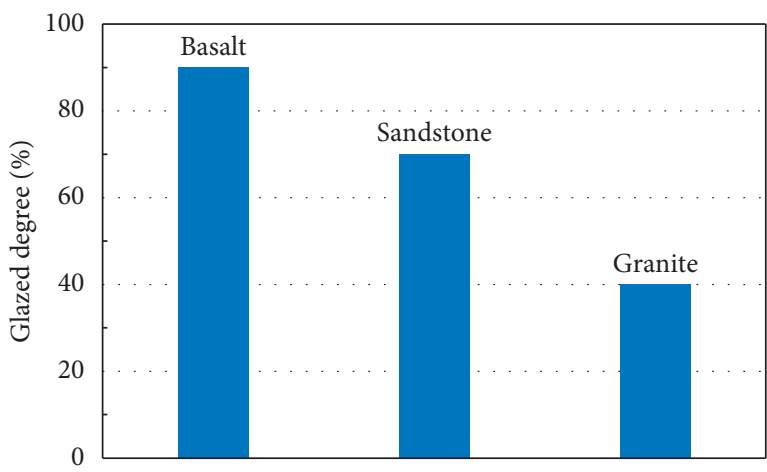

(b)

FIGURE 5: Comparison between quartz content and glazed degree of rock. (a) Quartz content in original rock. (b) Glazed degree of the rock after laser irradiation. 


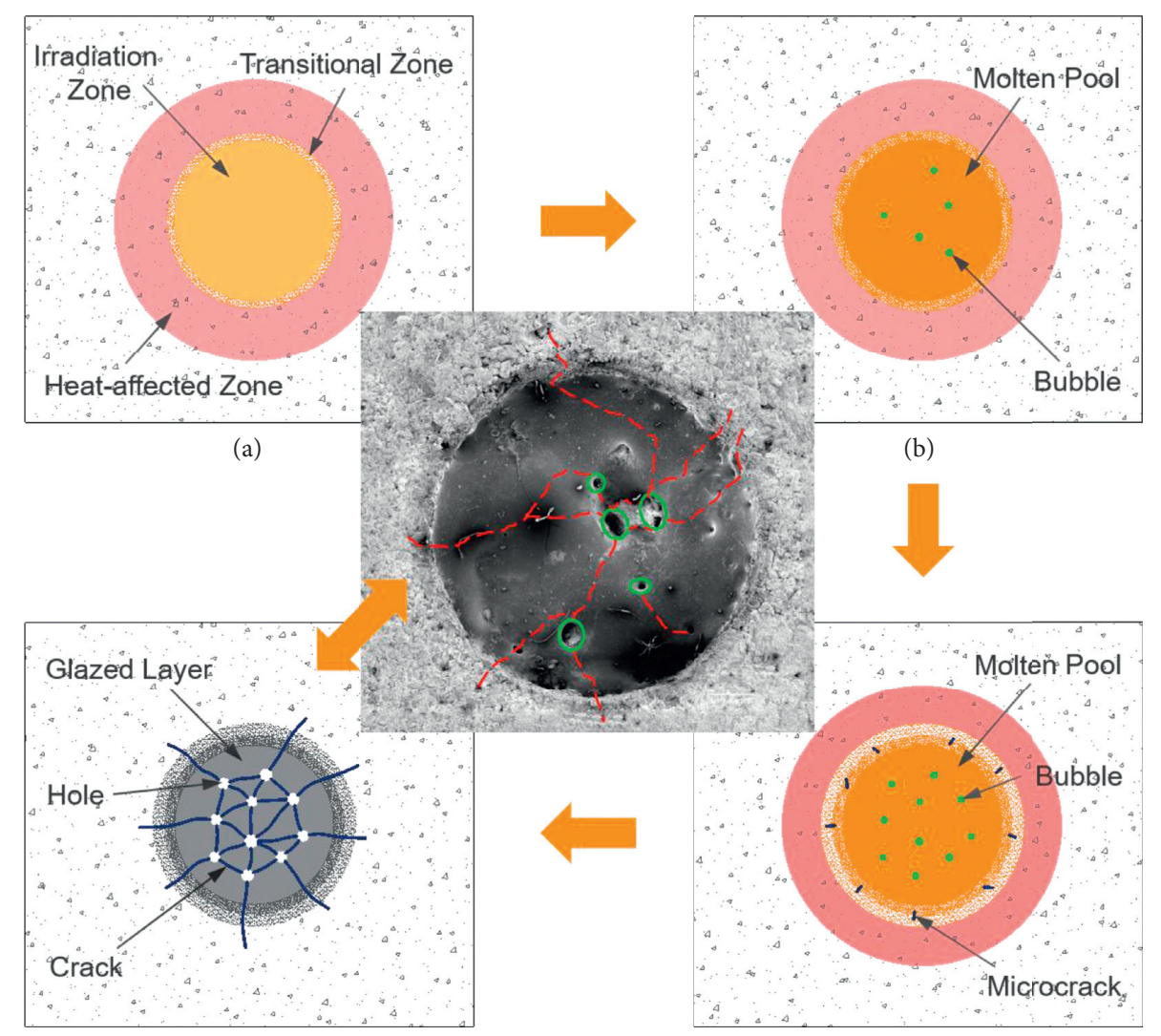

(d) (c)

Figure 6: Schematic diagram of failure process of the rock by fiber laser irradiation.

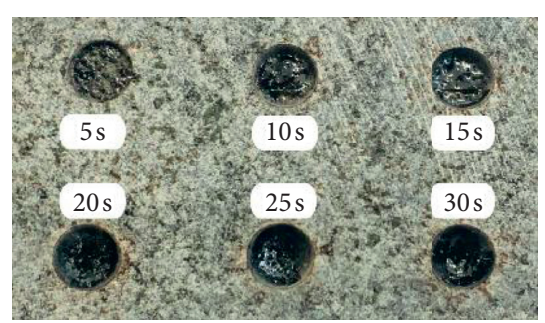

(a)

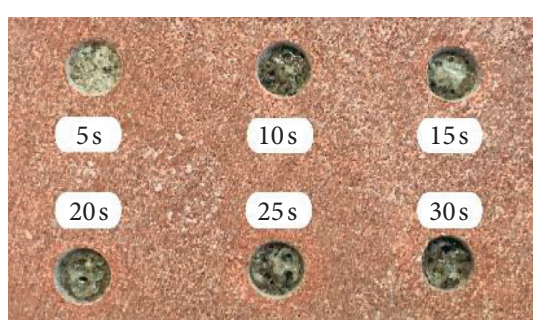

(b)

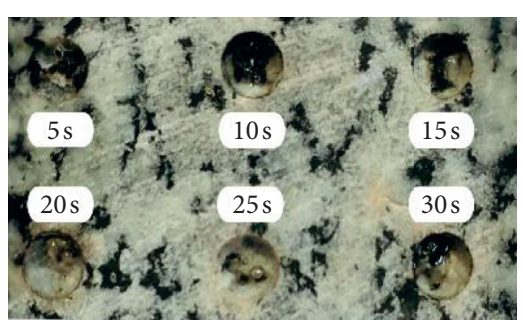

(c)

FiguRE 7: The morphologies of laser perforated rock under different laser irradiation time. (a) Basalt. (b) Sandstone. (c) Granite.

addition, it is also shown that ROP of granite is higher than that of sandstone and basalt, which is mainly due to its lower strength.

\subsubsection{Effect of the Laser Power in Laser Perforating. The} morphologies of basalt, sandstone, and granite under different laser power are shown in Figure 11. When the laser power is low $(<30 \mathrm{~W})$, the perforation is shallow, the shape is irregular, and the glazed layer is hardly produced. With the increase of the laser power, the perforation becomes deeper, and the glazed layer in the hole increases more obviously.

Figure 12 shows that both the laser perforation depth and the ROP increase with the laser power. The greater the laser energy, the higher the breaking rate of the rock and the larger the crushing volume. In addition, it is shown that the perforation depth of basalt is lower than that of sandstone and granite. It is mainly due to the higher strength of basalt, which required more laser power for breaking. Moreover, the higher content of quartz in sandstone and granite with lower glazed degree causes less hindering effects to the transmission of laser energy by the glazed layer; thus, the ROP and perforation depth of sandstone and granite is higher than that of basalt.

The correlation between SE and laser power is shown in the Figure 13. With the increase of laser power, SE initially decreases and then increases with a $\mathrm{V}$-shaped distribution. At lower power, the rock temperature is not enough to make the rock melt, and the main destructional form of the rock is thermal stress failure, so the energy utilization rate is high, 


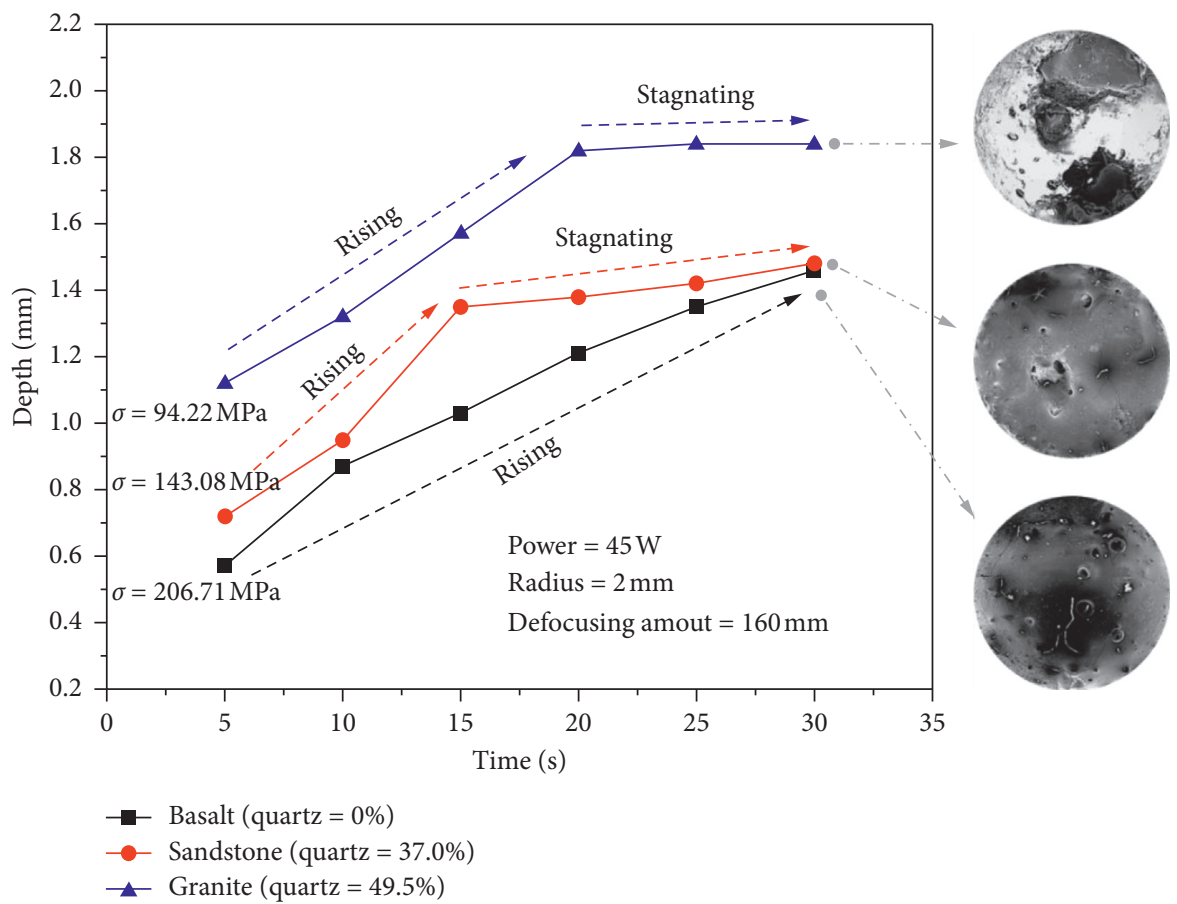

FIGURE 8: Effect of the laser irradiation time on the rock perforation depth.

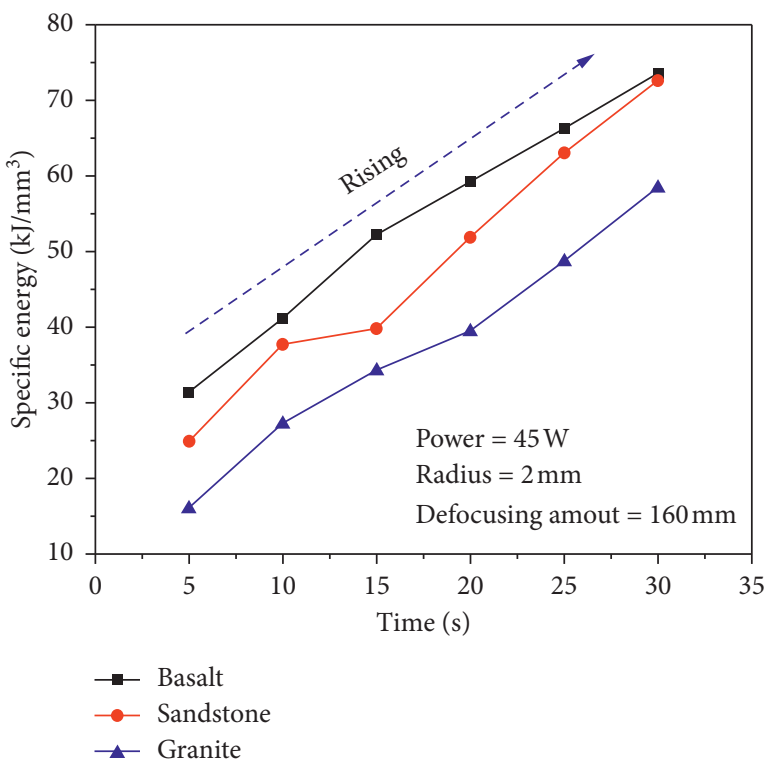

FIgURE 9: Effect of the laser irradiation time on specific energy (SE) of laser perforating.

and SE gradually decreases. When the power increases to a certain value, the rock begins to melt and produces glazed layer, which hinders the laser energy transmission, and the decrease of energy utilization leads to the increase of SE. It can be inferred from the " $V$ " pattern that there exists an optimal power to maximize the perforation efficiency.

3.2.3. Evolutionary Process of the Rock Perforation by Fiber Laser. According to the above analysis of experiment results,

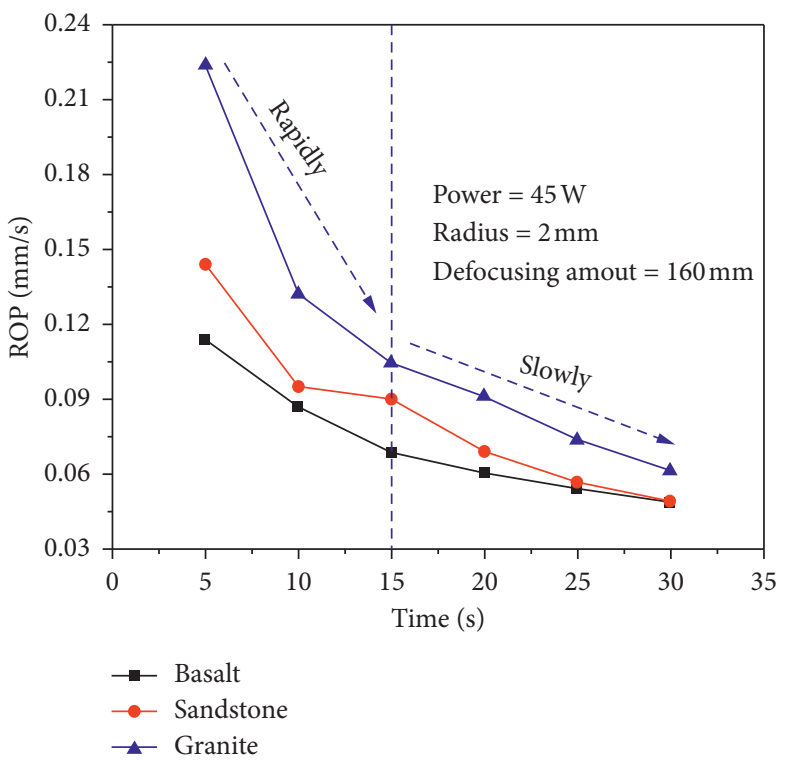

Figure 10: Effect of the laser irradiation time on ROP (rate of penetration) of laser perforating.

the formation process of rock laser perforation is shown in Figure 14, which can be summarized as four stages. Initially, high temperature on the rock surface is generated under the laser irradiation, which gradually conducts to the inside to form a heat-affected zone (Figure 14(a)). Laser irradiates the rock continuously, and the rock melts gradually. During the melting, some original pores are filled, then the molten pool drops, and the perforation is preliminarily formed (Figure 14(b)). The molten pool is boiling under the continuous irradiation of laser, where the sealed gas in the 


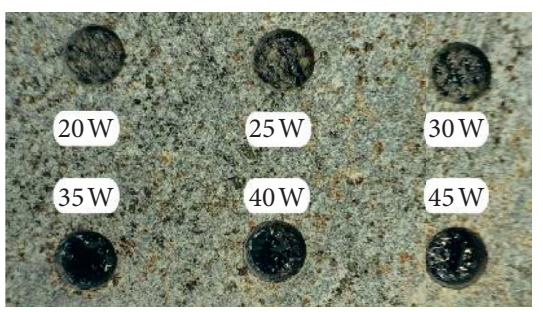

(a)

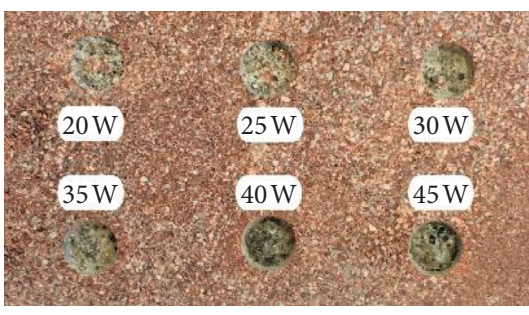

(b)

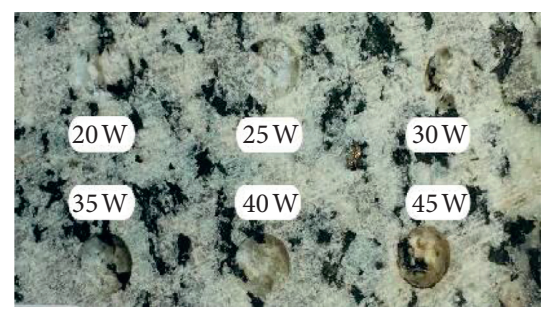

(c)

FIGURE 11: Morphologies of laser perforated rock under different laser power. (a) Basalt. (b) Sandstone. (c) Granite.

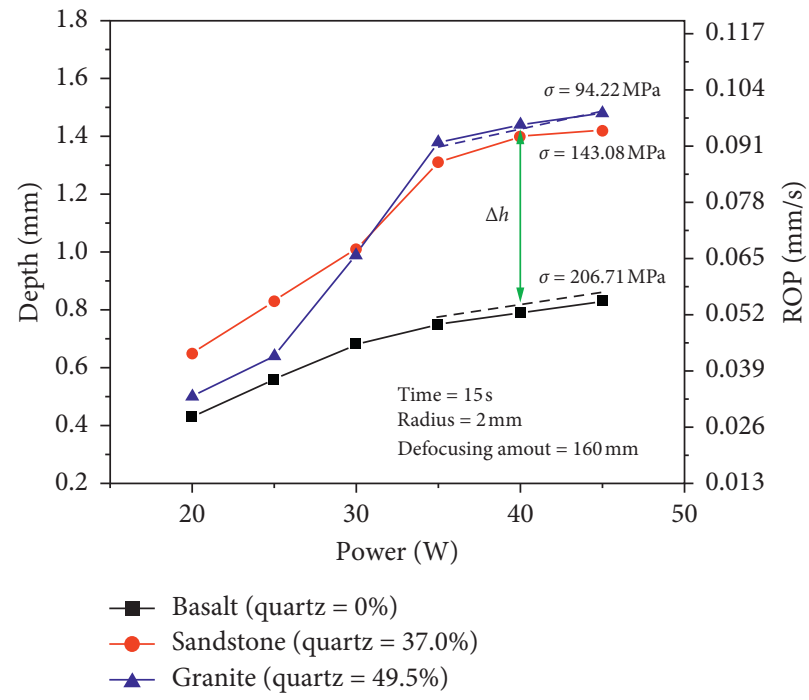

FIGURE 12: Effect of laser power on the rock perforation depth and ROP (rate of penetration).

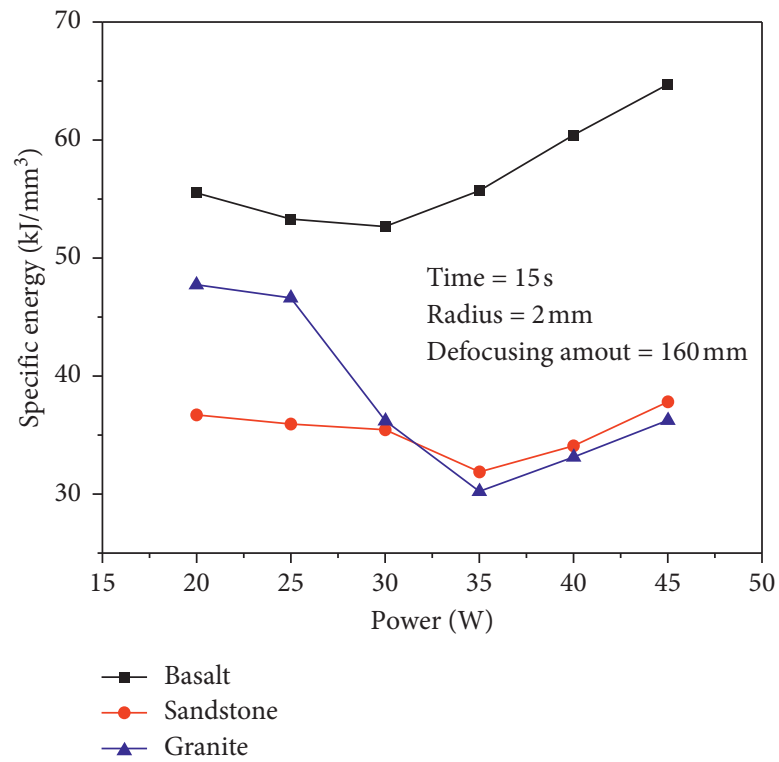

FIGURE 13: Effect of the laser power on specific energy (SE) of laser perforating.

original rock and the thermal decomposed gas of especial minerals escape to form bubbles. Meanwhile, some molten rock droplets splash, and some special components gasify and condense into white floccule escape, causing the perforation continues to deepen; many microcracks appear in the heataffected zone near the molten pool due to the thermal stress 


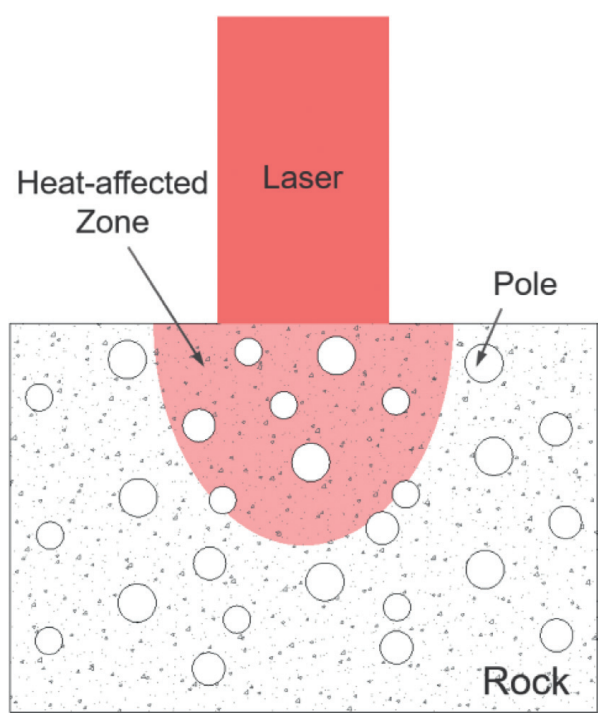

(a)

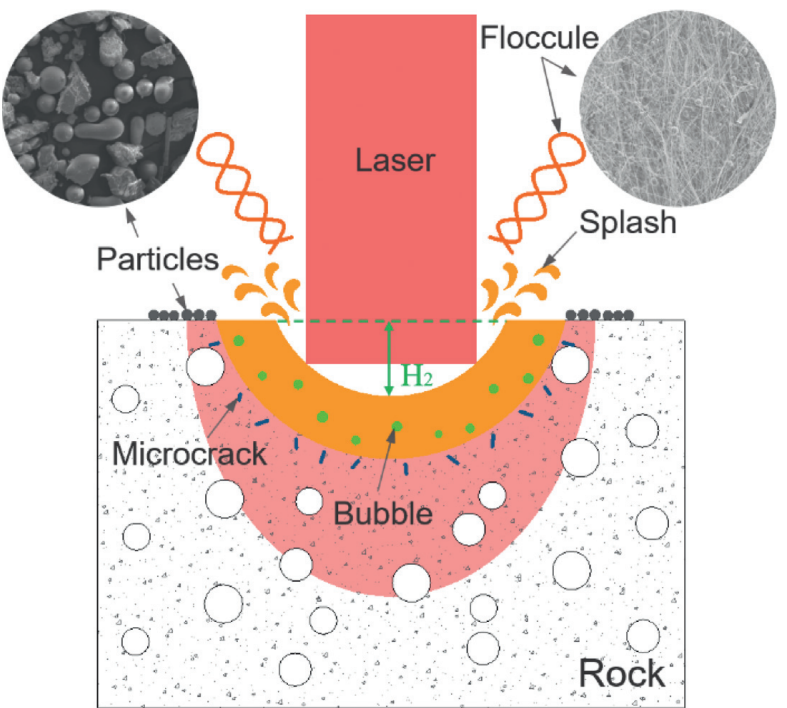

(c)

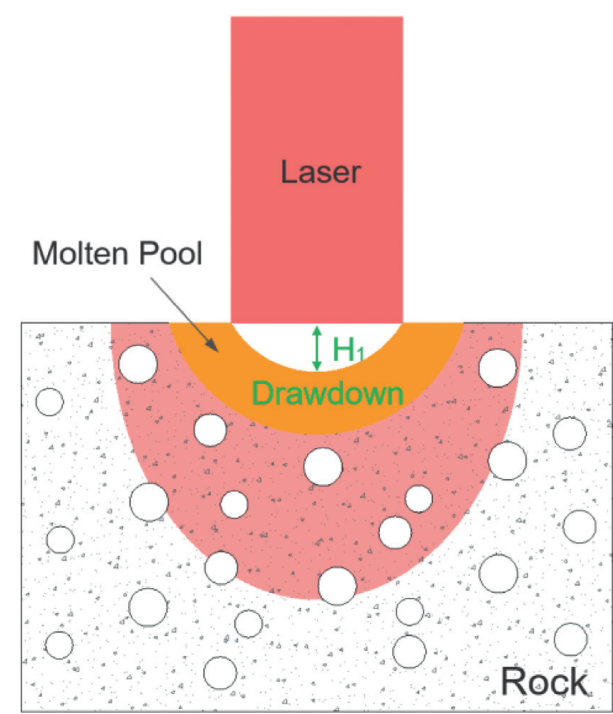

(b)

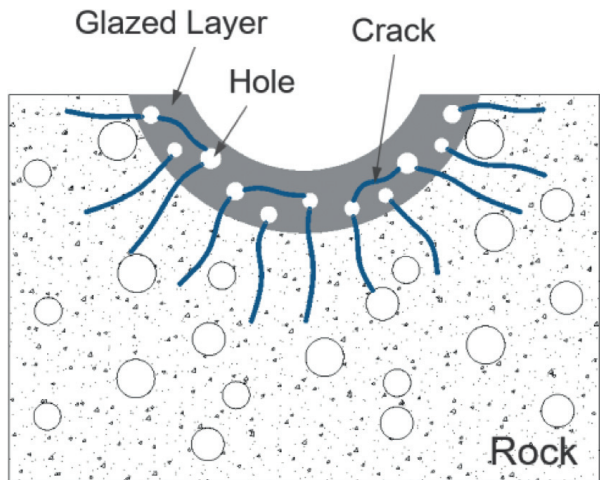

(d)

FIGURE 14: Schematic diagram of evolutionary process of the rock laser perforation.

(Figure 14(c)). The molten pool condenses when the laser irradiation is completed. The rock volume shrinks, and the bubbles in the molten pool expand, which coagulate to remain some slightly larger holes or vacuoles in glazed layer. Cracks appear around the holes and extend to outwards by the thermal stress. A divergent cracks net is formed around the glazed layer after the condensation (Figure 14(d)).

\section{Conclusions}

Fiber laser rock perforation experiments on basalt, sandstone, and granite were conducted. Based on the analysis of rock surface morphologies and composition tests, the surface failure characteristics of the lased rock are summarized. Based on the analysis of the perforation depth test results and hole characteristics under different laser parameters, the mechanism of rock laser perforation is also studied. The following conclusions could be drawn:

(1) The main features of rock failure in fiber laser perforation are thermal cracks and glazed layer. The surface cracks of the lased rock are mainly generated by thermal stress for the large temperature difference, and the glazed layer is mainly formed by rock melting and condensing. The holes and vacuoles in the glazed layer are related to the escape of the sealed gases in the original pores and the pyrolytic gases by special mineral components. It is also found higher quartz content could help reduce the glazed degree of rock. Comprehensive results showed that the laser rock perforation is mainly formed by thermal fractures, the decline of molten pool, and the evaporating and splashing of the special melted rock components. 
(2) The depth of rock perforation and SE (specific energy) usually increase with the laser irradiation time, while the ROP (rate of penetration) gradually decreases. With the increase of laser power, the perforation depth and ROP gradually increase, while the SE shows a V-shaped profile which initially decreases and then increases. Therefore, there is an optimal power for each rock type that maximizes perforation efficiency.

(3) The strength of rock is the main factor affecting laser perforation efficiency. Lower rock strength results in higher ROP, deeper perforation depth, and lower SE. In addition, the glazed degree also influences the perforation depth and ROP of the lased rock. The higher quartz content in the rock could reduce the overall glazed degree of the perforation and then help to improve the perforating.

\section{Data Availability}

The data used to support the findings of this study are included within the article.

\section{Conflicts of Interest}

The authors declare that they have no conflicts of interest regarding the publication of this paper.

\section{Acknowledgments}

The research was funded by National Natural Science Foundation of China (nos. 51674267 and 51874310).

\section{References}

[1] T. Kobayashi, S. Kubo, M. Ichikawa, and M. Nakamura, "Drilling a 2-inch in diameter hole in granites submerged in water by $\mathrm{CO}_{2}$ lasers of presentation," in Proceedings of the SPE/IADC Drilling Conference and Exhibition, Amsterdam, Netherlands, March 2009.

[2] K. Ohtani, D. Numata, K. Takayama, T. Kobayashi, and K. Okatsu, "Experimental study of underwater rock drilling using a pulsed Ho:YAG laser-induced jets," Shock Waves, vol. 19, no. 5, pp. 403-412, 2009.

[3] I. Batarseh, H. Abass, A. Al-Mulhem, and S. Habib, "High power laser application in openhole multiple fracturing with an overview of laser research; past, present and future of presentation," in Proceedings of the SPE Saudi Arabia Section Technical Symposium and Exhibition, Al-Khobar, Saudi Arabia, April 2012.

[4] W. Schulz, U. Eppelt, and R. Poprawe, "Review on laser drilling I. Fundamentals, modeling, and simulation," Journal of Laser Applications, vol. 25, no. 1, Article ID 012006, 2013.

[5] W. Adeniji, "The applications of laser technology in downhole operations-a review of presentation," in Proceedings of the International petroleum techonlogy conference, Doha, Qatar, January 2014.

[6] F. Buckstegge, T. Michel, M. Zimmermann, S. Roth, and M. Schmidt, "Advanced rock drilling technologies using high laser power," Physics Procedia, vol. 83, pp. 336-343, 2016.

[7] I. Batarseh, R. Graves, P. San-Roman-Alerigi, and K. Chand, "Laser perforation: lab to the field of presentation," in
Proceedings of the Abu Dhabi International Petroleum Exhibition \& Conference, Abu Dhabi, UAE, October 2017.

[8] M. R. Erfan, K. Shahriar, M. Sharifzadeh, M. Ahmadi, and M. J. Torkamany, "Moving perforation of rocks using long pulse Nd:YAG laser," Optics and Lasers in Engineering, vol. 94, pp. 12-16, 2017.

[9] G. D. Gautam and A. K. Pandey, "Pulsed Nd:YAG laser beam drilling: a review," Optics \& Laser Technology, vol. 100, pp. 183-215, 2018.

[10] R. M. Graves, A. Araya, B. C. Gahan, and R. A. Parker, "Comparison of specific energy between drilling with high power lasers and other drilling methods of presentation," in Proceedings of the SPE Annual Technical Conference and Exhibition, San Antonio, TX, USA, October 2002.

[11] Z. Xu, C. B. Reed, G. Konercki et al., "Specific energy for pulsed laser rock drilling," Journal of Laser Applications, vol. 15, no. 1, pp. 25-30, 2003.

[12] R. A. Parker, B. C. Gahan, R. M. Graves, B. Samih, X. Zhiyue, and C. B. Reed, "Laser drilling: effects of beam application methods on improving rock removal of presentation," in Proceedings of the SPE Annual Technical Conference and Exhibition, Denver, CO, USA, October 2003.

[13] M. Ahmadi, M. R. Erfan, M. J. Torkamany, and G. A. Safian, "The effect of interaction time and saturation of rock on specific energy in ND:YAG laser perforating," Optics \& Laser Technology, vol. 43, no. 1, pp. 226-231, 2011.

[14] M. Ahmadi, M. R. Erfan, M. J. Torkamany, and J. Sabbaghzadeh, "The effect of confining pressure on specific energy in Nd:YAG laser perforating of rock," Optics \& Laser Technology, vol. 44, no. 1, pp. 57-62, 2012.

[15] M. Bakhtbidar, "Experimental analysis of laser drilling impacts on rock properties," International Journal of Petroleum and Geoscience Engineering, vol. 1, pp. 106-114, 2013.

[16] H. Kariminezhad, H. Amani, and M. Moosapoor, "A laboratory study about laser perforation of concrete for application in oil and gas wells," Journal of Natural Gas Science and Engineering, vol. 32, pp. 566-573, 2016.

[17] A. Bharatish, B. Kishore Kumar, R. Rajath, and H. N. Narasimha Murthy, "Investigation of effect of $\mathrm{CO}_{2}$ laser parameters on drilling characteristics of rocks encountered during mining," Journal of King Saud University-Engineering Sciences, vol. 31, no. 4, pp. 395-401, 2019.

[18] M. Li, B. Han, Q. Zhang, S. Zhang, Q. He, and Q. He, "Investigation on rock breaking for sandstone with high power density laser beam," Optik, vol. 180, pp. 635-647, 2019.

[19] R. M. Graves, S. Batarseh, R. A. Parker, and B. C. Gahan, "Temperatures induced by high power lasers: effects on reservoir rock strength and mechanical properties of presentation," in Proceedings of the SPE/ISRM Rock Mechanics Conference, Irving, TX, USA, October 2002.

[20] S. Batarseh, B. C. Gahan, R. M. Graves, and R. A. Parker, "Well perforation using high-power lasers of presentation," in Proceedings of the SPE Annual Technical Conference and Exhibition, Denver, CO, USA, October 2003.

[21] F. Yan, Y. Gu, Y. Wang et al., "Study on the interaction mechanism between laser and rock during perforation," Optics \& Laser Technology, vol. 54, pp. 303-308, 2013.

[22] B. Han and L. M. Yan, "Evaluation of drillability of rock breaking assisted by laser," Journal of Petroleum and Natural Gas, vol. 36, pp. 94-97, 2014.

[23] S. Jamali, V. Wittig, J. Börner, R. Bracke, and A. Ostendorf, "Application of high powered laser technology to alter hard rock properties towards lower strength materials for more efficient drilling, mining, and geothermal energy production," 
Geomechanics for Energy and the Environment, vol. 20, pp. 100-112, 2019.

[24] P. San-Roman-Alerigi, P. Dijk, V. Lube, and P. Gilles Lubineau, "Characterizing the effects of high power laser performance on carbonate rocks of presentation," in Proceedings of the Middle East Geosciences Conference and Exhibition, Manama, Bahrain, March 2018.

[25] M. Hu, Y. Bai, H. Chen, B. Lu, and J. Bai, "Engineering characteristics of laser perforation with a high power fiber laser in oil and gas wells," Infrared Physics \& Technology, vol. 92, pp. 103-108, 2018.

[26] K. R. Agha, H. A. Belhaj, S. Mustafiz, N. Bjorndalen, and M. R. Islam, "Numerical Investigation of the prospects of high energy laser in drilling oil and gas wells," Petroleum Science and Technology, vol. 22, no. 9-10, pp. 1173-1186, 2004.

[27] M. Li, Y. Wang, Y. Wang, C. Zhang, and J. Liu, "Theoretical analysis and numerical simulation of laser rock breaking," Chinese Journal of Lasers, vol. 35, no. 8, pp. 1245-1249, 2008.

[28] M. Li, B. Han, S. Zhang, L. Song, and Q. He, "Numerical simulation and experimental investigation on fracture mechanism of granite by laser irradiation," Optics \& Laser Technology, vol. 106, pp. 52-60, 2018.

[29] R. Ndeda, S. E. M. Sebusang, R. Marumo, and E. O. Ogur, "On the role of laser pulses on spallation of granite," Lasers in Manufacturing and Materials Processing, vol. 4, no. 2, pp. $60-75,2017$.

[30] R. A. Ndeda, S. E. Sebusang, R. Marumo, and E. O. Ogur, "Numerical model of laser spallation drilling of inhomogeneous rock," IFAC-PapersOnLine, vol. 50, no. 2, pp. 43-46, 2017. 